\title{
The Pediatric Neurologist as Expert Witness with Particular Reference to Perinatal Asphyxia
}

\author{
Michael I. Shevell
}

\begin{abstract}
The frequency of litigation related to alleged medical malpractice is increasing in Canada. For the neurologist, involvement in such litigation most often takes place in the context of acting as an expert witness and, for the pediatric neurologist, the most common clinical situation for which expertise is requested is that of possible perinatal asphyxia. The medical expert's primary role is to provide necessary guidance and assistance to the court, which may permit the rendering of decisions that are scientifically valid. This article will review the attributes of the medical expert witness. Aspects of perinatal asphyxia cases under litigation that commonly require the assistance of pediatric neurology expertise such as etiology, timing, extent of disability and life expectancy will also be reviewed in detail. The aim is to provide for the neurologist a clearer understanding of the responsibilities inherent in this increasing professional role.
\end{abstract}

RÉSUMÉ: Le neuropédiatre en tant que témoin expert: considérations sur les causes d'asphyxie périnatale. La fréquence des litiges pour faute médicale présumée augmente au Canada. Pour le neurologue, son implication dans de telles causes est la plupart du temps comme témoin expert et pour le neuropédiatre, la situation clinique la plus fréquente pour laquelle on demande son expertise est lorsqu'il y a possibilité d'asphyxie périnatale. Le rôle principal de l'expert médical est de fournir les conseils et l'aide nécessaires à la cour afin que les décisions rendues soient scientifiquement valides. Cet article revoit les qualités du témoin expert médical. Les aspects des cas d'asphyxie périnatale faisant l'objet de litiges qui requièrent souvent l'expertise du neuropédiatre tels l'étiologie, la chronologie, le degré d'invalidité et l'espérance de vie sont également revus en détail. Le but de cet article est de fournir au neurologue une meilleure compréhension des responsabilités inhérentes à cette fonction professionnelle à laquelle on a de plus en plus souvent recours.

Can. J. Neurol. Sci. 2001; 28: 107-112

Recent years have seen a proliferation in medical malpractice litigation in Canada. Furthermore, the subject matter of such litigation has become increasingly complex. ${ }^{1}$ These trends have combined to result in a much greater usage of medical experts in the judicial process. ${ }^{2}$ Since our legal system is, at root, an adversarial one, both sides see fit to retain experts, and medical malpractice litigation can become a battle of competing experts, the outcome of which is significantly dependent on the expert's particular qualifications and presentation. ${ }^{2}$ In this article, the author will review the features and requirements of the medical expert witness within the framework of the Canadian judicial system. The author will then examine the situation of alleged perinatal asphyxia, which is the most common legal setting in which the expertise of the pediatric neurologist is requested.

\section{EXPERT WITNESS}

The most common reason for involvement of a pediatric neurologist in legal proceedings is as an expert witness. ${ }^{3}$ An expert witness is one who is permitted to give opinion evidence in distinction to a "fact witness" who can attest to what has been personally observed at first hand. ${ }^{4}$ Black's Law Dictionary defines the expert witness as one who "possesses superior knowledge respecting a subject about which persons having no particular training are incapable of forming an accurate opinion or deciding correct conclusions". 5

The status as an "expert" in legal proceedings is a unique and specific determination that is a function of the subject matter at issue. $^{1,2}$ It is the particular qualification of an individual with

Presented in part at the 35th Meeting of the Canadian Congress of Neurological Sciences, June 2000.

From the Departments of Neurology/Neurosurgery, Pediatrics and Human Genetics, McGill University, Montreal, and Division of Pediatric Neurology, Montreal Children's Hospital, Montreal, Quebec, Canada.

Received August 30, 2000. AcCePted infinalform December 5, 2000. Reprint requests to: Michael Shevell, Montreal Children's Hospital, 2300 Tupper Street, Room A-514, Montreal, Quebec, Canada H3H 1P3 
relation to the subject matter under consideration that establishes this status. Wide latitude in such a determination has traditionally existed within the legal system, and it is ultimately within the purview of the responsible trial judge. ${ }^{4}$ Expert status is based on relevant qualifications pertaining to the domains of knowledge, skill, experience, training and education. Objective criteria utilized in assessing expertise in the medical sphere include appropriate board certification, practice profile, academic appointments, publication record (both peer reviewed and definitive texts), research undertaken, and professional standing in provincial, national and international organizations.

The Supreme Court of Canada has ruled on the criteria necessary to permit the admissibility of expert evidence. ${ }^{6}$ Four criteria were highlighted and these include: 1) that the evidence be relevant to the case under consideration, 2) that the evidence be necessary in assisting the trier of fact (judge alone or judge and jury), 3) that the evidence not be excluded under another exclusionary rule, and 4) that the evidence be presented by an expert who is properly qualified in the domain of interest. Specific features to establish this fourth criteria were not elaborated upon in this decision.

In all legal proceedings, the expert witness'primary role is to provide necessary assistance and guidance to both counsel and the court. ${ }^{4}$ The expert's particular knowledge and frame of reference provides a source for clarification of complex issues and advice and understanding in pursuing these issues. Most importantly, the expert is the means by which the scientifically valid is established within the legal framework. Legal proceedings are not the forum for establishing new science and theories of causation. ${ }^{2}$ Proper peer review and validation of novel theories is essentially impossible in legal proceedings. However, it needs to be noted that the civil courts operate on "a more probable than not" (sometimes explained as greater than $50 \%$ ) burden of proof, rather than the near certainty often demanded of science and medical decision-making.

The "ideal" expert possesses many characteristics. ${ }^{7,8}$ These include intellectual honesty and experience. The expert communicates effectively, clearly and promptly, both orally and in writing. An expert needs to maintain independence and decline to give assessments that are inconsistent with the expert's own considered objective opinion. The expert's remuneration preferably should be fixed (either on an hourly or paid basis) prior to undertaking involvement and thus not influenced by the outcome of the case (i.e. contingency). The expert avoids either advocacy (this is the responsibility of legal counsel) or statements that are legal conclusions (e.g. negligence). The expert, to preserve credibility, confines his/her opinion to his/her own area of expertise and does not hesitate to identify areas of uncertainty or doubt when such exist. The expert's opinion rests wherever possible on that which is scientifically valid and accepted by peer review. Therefore, the expert will need to demonstrate a consistency of approach and reasoning across different cases considered by that expert. Changes in the expert's opinion and approach over time reflects the temporal evolution in the understanding of a particular area underscored by scientific advances and therefore at all times should be consistent with such advances.

Additional desirable characteristics of the expert witness include a sound knowledge of the topic under consideration and familiarity with the particular case materials under review. To avoid the spectre of the "expert witness for hire", the expert should be in current active practice and not derive the majority of professional income from the providing of expertise in legal domains. ${ }^{3}$ The opinion of the expert must rest on a thorough review of all relevant materials pertaining to the case at hand. The temptation to give an opinion based on fragmentary or partial records needs to be firmly resisted. Necessary materials pertaining to providing an expert opinion include a review of the complete medical dossier, relevant laboratory investigations and discovery transcripts. In certain circumstances, the rules of court permit the expert to conduct an interview and physical examination of the plaintiff. The opinion needs to be grounded within the framework of the review and an understanding of the relevant and up-to-date scientific literature.

An appearance of bias to an observer may exist on the part of an expert witness as this individual is recruited, retained, paid for and ultimately serves at the discretion of legal counsel. While the potential for bias exists, it is this author's opinion that it needs to be minimized and eliminated if possible. This is only possible if the expert restricts himself to providing an intellectually honest opinion that is scientifically valid. The expert's personal integrity and comfort with the opinion rendered is essential in this regard. The expert must "call it as he or she sees it" and strongly resist the temptation to see the facts of a case as others may wish.

Bias is also minimized by undertaking a nonbinding initial review following the request by counsel to consult. It is suggested that the opinion of the expert be rendered verbally to requesting counsel, and a mutual decision to continue to collaborate can then be undertaken. Requesting counsel will need to recognize that their claim or defense may not be scientifically valid if they are so advised by more than one expert consulted.

Bias is further minimized by avoiding advocacy and not undertaking the simultaneous and incompatible roles of treating physician and expert witness. This latter point can be extended to include the avoidance of participation in cases in which patient care has been provided by professional colleagues either at the same institution or an affiliated institution in which the expert witness exercises the practice of medicine. Given the paucity of pediatric neurologists in Canada, geographical isolation and concentration of specialty services in some locales, as well as linguistic differences, may challenge counsel's recruitment of the pediatric neurologist as an expert witness.

The basis for the expert opinion must be set out in the expert's written report to requesting counsel. Essential features of this report include: 1) identifying explicitly the purposes for which the report is prepared, 2) stating the expert's relevant personal credentials and experience that establishes expert status, 3) the precise documents and materials reviewed upon which the opinion rests, 4) the facts of the case under question with a precise chronology, and 5) the expert's assessment and conclusions relevant to the original questions posed by legal counsel.

It is advisable to provide a preliminary draft of such a report (so labelled) to legal counsel for review. This is done not to shape or alter the fundamental nature of the expert's conclusions, but to avoid errors of facts, opinions outside of the domain of expertise and legal conclusions. It is also necessary to assure that the 
specific questions posed originally have been responded to, based on the legal burden of proof being "more probable than not". It is important to recognize that the expert's final report will be made available to opposing counsel and will be the basis of any deposition or court testimony on the part of the expert that may result.

At present less than $10 \%$ of medical malpractice litigation in Canada comes to trial. ${ }^{9}$ Pretrial settlement or discontinuance of an action is the usual disposition and this is often assisted by expert opinion. If there is a trial, the testimony of the expert witness in open court may be required. The expert's qualifications may be challenged by opposing counsel. Most certainly, the expert's opinion will be tested during crossexamination. It is essential that the expert have a clear idea of the opinion given and the basis in substantiated facts and reasoning for that opinion. The rationale for rejection of possible alternative opinions will likely be explored. The deportment of the expert in court is often scrutinized. The expert needs to demonstrate a sound grasp of the material and respond clearly and expeditiously. The appearance of impartiality and the avoidance of explicit bias or advocacy are necessary. The expert needs to convey to the trier of facts, his/her primary role of assisting the court in understanding relatively complex issues.

In 1996, the Ethics and Practice Committee of the Child Neurology Society published a result of the survey of the Society's membership. ${ }^{3}$ The survey featured a $25 \%$ response rate and documented that $42 \%$ of the responding members had been the object of a medical liability lawsuit. Ninety percent had reviewed cases for legal counsel in the capacity as an expert witness, with $13 \%$ reviewing more than 10 cases annually with compensation typically ranging from \$200 to \$300 US (1993) with a reported high of $\$ 500$ US per hour. Of note, $70 \%$ of those surveyed felt the system was unfair in its process and felt there was a need for peer review of expert witness conduct.

This last observation highlights that presently there does not exist any systematic review of the conduct and performance of an expert witness. ${ }^{2,7,10}$ Oversight is not provided by any professional organization relevant to the practice of pediatric neurology and it is unclear if the expert witness'role is an aspect of medical practice, a scholarly activity or another endeavour. Suggestions for expert witness regulation put forward in the literature have included peer review, journal publication of testimony transcripts, the removal of generally accepted legal immunity, and the possibility of as yet undefined sanctions by professional organizations. ${ }^{10,11}$ None of these suggestions have been put into place and have been rejected largely on the basis of being unwieldy or unenforceable. Moreover, any out-of-court method of reviewing the actions of an expert witness could be viewed as an attempt to interfere with the judicial process.

\section{Perinatalasphyxia}

The situation in which a pediatric neurologist is most likely to be requested to act as an expert is that of a child whose impairment and resulting disabilities and handicaps are the result of an alleged perinatal asphyxia secondary to obstetrical mismanagement. ${ }^{12}$ Within this setting, the expertise of a pediatric neurologist is focused on the following four main issues:
1. Causation and precise determination of etiology - is asphyxia the root cause for the child's observed disabilities?

2. The timing of the asphyxia - is it antenatal, perinatal (i.e. intrapartum) or postnatal in origin?

3. The precise description of the child's disabilities and handicaps.

4. The estimated life expectancy of the child/plaintiff.

The first two issues contribute to the court's understanding and determination of legal responsibility, while the latter two issues contribute to determination of the cost of legal settlement if the defendant is ultimately held responsible.

The typical child/plaintiff in "compromise baby" cases would have a variant of cerebral palsy. Cerebral palsy is defined as a nonprogressive motor deficit. ${ }^{13}$ It is properly conceptualized as a symptom complex, essentially a description of physical findings and their evolution (i.e. lack thereof) over time for which there is a multitude of possible heterogeneous causes. ${ }^{14}$ Cerebral palsy is the later neurologic disability most consistently linked with perinatal asphyxia, ${ }^{12}$ yet it is important to note that perinatal asphyxia is but one cause amongst many of this symptom complex. Outcomes other than cerebral palsy (such as global developmental delay ${ }^{15}$ ) may also occur as a result of perinatal asphyxia. Population-based epidemiologic studies have consistently shown that less than $20 \%$ of cases of cerebral palsy can be attributed to perinatal asphyxia and, in the majority of cases of cerebral palsy, the cause remains unknown. ${ }^{14,16-18}$ Despite advances in fetal monitoring and their widespread use, which has led to rising rates of obstetrical interventions aimed at preventing the occurrence of perinatal asphyxia, the frequency of cerebral palsy has remained essentially unchanged over time..$^{12,19}$

Perinatal asphyxia is defined as impaired respiratory gas exchange, which leads to progressive hypoxemia, hypercapnea and acidosis that occurs in relation to the act of partuition. ${ }^{20} \mathrm{It}$ operates on a threshold and continuum paradigm. ${ }^{21}$ Essentially, there is a high threshold above which injury may occur, and beyond this threshold a direct relationship exists between the degree of asphyxia and the severity of subsequent injury. In response to asphyxia, there is a redistribution of cardiac output, preferential blood flow to the brain, improved oxygen extraction, and decreased cerebral oxygen requirements. ${ }^{20}$ These physiological responses act in concert to protect the brain from injury. The actual progression of cerebral injury subsequent to asphyxia may be difficult to establish. ${ }^{20}$ Furthermore, there exists considerable interindividual variation in the newborn's response to injury that can be attributed to intrinsic resiliency. ${ }^{22}$

Increasingly there has been the recognition that prenatal factors and conditions may predispose to the occurrence of asphyxia during partuition, i.e. asphyxia is a consequence, rather than a cause, of impairment. ${ }^{23}$ Prenatal factors identified include genetic conditions, neuromuscular disorders, placental insufficiency (on the basis of vasculopathy or thromboses) and placental infections.

At present, no single definitive biomarker or gold standard for the diagnosis of perinatal asphyxia exists. ${ }^{24,25}$ Thus an operational definition is necessary. Markers of asphyxia have been identified that are antepartum, intrapartum or postpartum in their occurrence. Antepartum markers include the maternal report of decreased fetal movements, impaired fetal growth parameters, and a nonreactive nonstress test. ${ }^{20}$ The observation 
of these specific markers suggests a more chronic, as opposed to acute, process.

Intrapartum markers of asphyxia include meconium staining, especially if heavy and early (i.e. at the time of rupture of membranes), the detection of fetal heart rate abnormalities (e.g. late decelerations, variable decelerations, persistent bradycardia or tachycardia), significant metabolic acidosis in a cord sample or early infant sample ( $\mathrm{pH}$ less than 7.0, base excess greater than 12) or persistently low APGAR score (less than six beyond five minutes). ${ }^{20}$

The most important postpartum marker of asphyxia is the observation of a neonatal encephalopathy. ${ }^{26}$ This entity has been noted to be the single most consistent marker that asphyxia has indeed occurred (i.e. no encephalopathy, no asphyxia) and a necessary precondition to the later development of neurologic disability (i.e. no encephalopathy, no later disability attributable to asphyxia). ${ }^{23,25}$ Neonatal encephalopathy is characterized by alterations in consciousness, tone, ease of feeding and brain stem function. ${ }^{26}$ Early seizures that are often difficult to control, frequently occur in this setting. ${ }^{27}$ The encephalopathy can be graded according to standardized criteria into mild, moderate or severe categories that have some predictive value to later outcome. ${ }^{28}$ Additional postpartum markers include evidence of multi-organ dysfunction (especially the kidney, featuring acute tubular necrosis), ${ }^{29}$ electrophysiologic abnormalities and imaging changes. The electrophysiologic abnormalities include background changes on EEG (e.g. burst suppression pattern), ${ }^{30}$ persistently absent cortical potentials on somatosensory evoked response testing, ${ }^{31}$ increased interwave latencies on auditory brain stem evoked response testing ${ }^{32}$ and absent visual evoked responses. ${ }^{33}$ Imaging changes, either on CT or MRI, may be acutely observed, such as cerebral edema or remote observations such as cerebral atrophy. ${ }^{34,35}$ Recent imaging advances (e.g. diffusion weighted MRI) have increased our capability to detect both the acute and chronic consequences of asphyxial injury ${ }^{36}$ as well as previously unsuspected subtle brain malformations. ${ }^{37}$ Imaging correlates of patterns of asphyxial injury are also well established. ${ }^{38}$

It has become apparent that the markers listed above, when used singly and in isolation, have low specificity and sensitivity for the definitive diagnosis of perinatal asphyxia. ${ }^{24}$ There are many other causes besides asphyxia for their occurrence. They also possess, in isolation, a very high false positive rate. Thus there has been a definite trend, both clinically and in research, away from a single marker definition for perinatal asphyxia. ${ }^{24,39}$ For reliable and certain diagnosis of asphyxia, a constellation of markers needs to be present concurrently in a specific case.

Two consensus statements addressing the issue of the reliable diagnosis of perinatal asphyxia have been issued in the past decade. The first is the joint statement of the American College of Obstetrics and Gynecology and the American Academy of Pediatrics. ${ }^{40}$ Four criteria for the diagnosis of perinatal asphyxia were highlighted: 1) profound metabolic acidosis ( $\mathrm{pH}$ less than 7.0), 2) APGAR score less than or equal to five beyond five minutes, 3) the observation of a neonatal encephalopathy, and 4) the observation of multi-organ dysfunction.

The second is the international consensus statement published in the British Medical Journal. ${ }^{41}$ This statement addresses the specific question of when asphyxia can be diagnosed (i.e. ascribed) as the cause of a child's observed cerebral palsy.
Essential features for this diagnosis, according to this consensus statement, include both neonatal encephalopathy and documentation of profound metabolic acidosis. Supportive features include the occurrence of a sentinel event (e.g. abruptio, maternal hypotension, cord prolapse), depressed fetal heart rate tracings, APGAR scores less than six beyond five minutes, multi-organ dysfunction, and neonatal laboratory evidence (either electrophysiological or imaging) of an acute cerebral abnormality. Left unsaid in the consensus statement is the number of supporting features necessary for definitive diagnosis.

From the foregoing it is apparent that to reliably diagnose perinatal asphyxia, the expert witness needs to answer in the affirmative the following question: Are the observations of a particular case consistent with the occurrence of an asphyxial event? ${ }^{12}$ This can be done by approaching the case through temporally receding layers of evidence: 1) determining if the current examination and evolution over time is consistent with a cerebral palsy, 2) determining if there are postnatal findings consistent with asphyxia (specifically the occurrence of a significant neonatal encephalopathy plus other organ dysfunction and supportive laboratory evidence), 3) determining if there are intrapartum signs of asphyxia (e.g. persistently low APGAR scores and profound metabolic acidosis), and 4) determining if there is the documentation of a proximate cause or sentinel event to explain asphyxia.

Concurrent with establishing the above positive lines of evidence, one needs to eliminate other possible etiologies or predisposing conditions to establish that perinatal asphyxia is more probable than not the cause for the child's/plaintiff's condition.

At this point, it is important to remember that not all asphyxiated infants develop cerebral palsy. ${ }^{42}$ It is still a subject of current research what other possible outcomes these children may have and their frequency. Within the medical-legal realm, one also needs to emphasize that ascribing asphyxia as a cause of cerebral palsy does not imply in any way that the obstetrical or medical care was either deficient or negligent. Furthermore, it should be noted that the expert witness called upon to establish the cause of perinatal asphyxia and cerebral palsy should have the following specific characteristics: 1) familiarity with cerebral palsy as a symptom complex, 2) familiarity with the causes of cerebral palsy, 3) familiarity with the care provided to individuals with cerebral palsy, and 4) familiarity with the current thinking and the reliable identification and diagnosis of cases of perinatal asphyxia. Ideally the individual should also be involved in research at the basic or clinical level pertaining to either cerebral palsy or perinatal asphyxia.

Once asphyxia is established as the operative etiology, the next aspect with respect to determining responsibility is identifying the timing of occurrence. Limitations exist regarding the precision of such a determination. The major issue is the timing of the injury with respect to the process of labour and delivery. This is a necessary prelude to answering the question of whether obstetrical intervention could have made a difference in ultimate outcome.

Clues to the timing of asphyxial injury can be searched for. ${ }^{43}$ Antepartum markers such as decreased fetal movements, a falloff in fetal growth parameters, or a nonreactive nonstress test suggest a more chronic process that predates the process of birth 
and delivery. ${ }^{20}$ Pathologic examination of the placenta that documents either chronic insufficiency (e.g. small size, infarct, accelerated maturation) or infection is increasingly utilized to specify timing of injury. ${ }^{44}$ Meconium staining of the placenta or the infant's skin or umbilicus requires up to eight hours of exposure and can be a useful clue if present. ${ }^{45,46}$ Imaging studies acutely within the first few days of life that document and follow the initial, often stereotyped, response to brain injury (i.e. progressive edema with increase of brain water content, small ventricles and loss of gray-white matter differentiation) provide attribution of a perinatal occurrence to asphyxia. ${ }^{34}$ Alternatively, if imaging studies document underlying developmental cerebral anomalies, a chronic predisposing condition can be surmised.

In anticipating attribution of legal responsibility, the cost of settlement needs to be addressed. This is a process called "quantum". The pediatric neurologist has expertise in two domains relative to this issue that can be offered to legal representatives and the court. The first is determination of actual current and future anticipated disability. This determination is a necessary precondition to a detailed future needs assessment and associated cost estimation. The formulation of the actual needs and cost assessment lies outside the expertise of the neurologist and is best undertaken by a qualified and experienced rehabilitation specialist.

The basis for disability determination is an independent medical examination by the expert of the plaintiff involving a detailed history and physical examination as well as a comprehensive review of recent relevant assessments carried out by ancillary specialists (e.g. occupational therapy, physiotherapy, psychology). The expert provides a description of the child's/plaintiff's current neurologic impairment and functional limitations in the domains of cognitive, mobility, feeding, toileting, recreational and activities of daily living skills.

Life expectancy of the child/plaintiff is an important component of determining the cost of settlement. Studies have shown that in the population of severely disabled individuals, life expectancy largely depends on the status of functional skills in the domains of mobility, feeding and continence. ${ }^{47}$ These studies have shown that the underlying etiology (if nonprogressive) or intercurrent conditions (e.g. epilepsy) contribute relatively little to prognosis regarding future life expectancy. Thus information obtained in disability determination is utilized in the life expectancy estimation.

Utilizing life tables from large population-based samples (e.g. California Department of Developmental Services) survival curves and life expectancy estimates that are age and genderspecific and stratified by functional skills are available in the literature ${ }^{47-49}$ These tables can be used for individual casespecific life expectancy estimation. Experts need to be comfortable with the methodology and statistics underlying these curves. They must also be cognizant of limitations of inferences drawn from population samples and applied to individual cases. The trend over time for individuals with severe disabilities is one of improving life expectancy, reflecting more home-based care and better supportive medical care. ${ }^{47}$

\section{CONCLUSION}

The pediatric neurologist has the knowledge and skills to assist and guide litigation concerning disabled individuals allegedly asphyxiated as newborns. The number of these cases and their substantial potential cost for settlement poses a significant challenge to the process of medical-legal litigation. The conscientious participation of the pediatric neurologist in these domains of professional expertise is a means to ensure that decisions ultimately made are indeed more scientifically valid than those decisions rejected. This is but one mechanism by which we can be certain that the cause of justice (i.e. correctly ascertaining and indemnifying liability) for these individuals is served.

\section{ACKNOWLEDGEMENTS}

MIS is a Chercheur Boursier Clinicien (Clinical Research Scholar) of the Fonds de recherche en santé de Québec.

Charles Hackland, partner at Gowling Lafleur Henderson (Ottawa, Ontario), provided insightful review of the manuscript during its preparation.

The author acknowledges the secretarial assistance of Judith Michael in manuscript preparation and the support of YCC and the $\mathrm{MCH}$ Foundation during manuscript writing.

The opinions expressed in this article are those of the author and no endorsement of those opinions by any organization with which the author is associated is implied.

\section{REFERENCES}

1. Middlemiss J. Examining the experts. National 2000;9:30-37.

2. Weintraub M. Expert witness testimony - an update. Neurol Clin 1999; 17:363-369.

3. Ethics and Practice Committees of the Child Neurology Society. Child Neurologist as Expert Witness. J Child Neurol 1998;13:398-401.

4. Weinstein JB. Expert witness testimony - a trial judge's perspective. Neurol Clin 1999;17:355-362.

5. Black's Law Dictionary. West Publishing Co. (6th Ed). 1990.

6. Mohan RV. 19942 S.C.R.9.

7. Weinstein J. Improving expert testimony. University of Richmond Law Rev 1986;20:473-494.

8. The Ikarian Reefer, 19932 Lloyd's Rep 68.

9. Canadian Medical Protective Association, 1999 Annual Report.

10. Weintraub MI. Expert witness testimony: a time for self-regulation? Neurology 1995;45:855-858.

11. Shield D. Peer-review of expert medical-legal testimony: a proposal for child neurology. J Child Neurol 1992;7:237-239.

12. Nelson KB. The neurologically impaired child and alleged malpractice at birth. Neurol Clin 1999;17:283-293.

13. Swaiman KF and Russman BJ. Cerebral Palsy. In: Swaiman KF, Ashwal S (Eds): Pediatric Neurology - Principles \& Practice (3rd Ed). St. Louis: Mosby 1999; 312-324.

14. Nelson KB, Ellenberg JH. Antecedents of cerebral palsy, multivariate analysis of risk. N Engl J Med 1986;315(2):81-86.

15. Shevell MI, Majnemer A, Rosenbaum P, Abrahamowicz M. Etiologic yield of subspecialists evaluation of young children with global developmental delay. J Pediatr 2000;136:593-598.

16. Blair E, Stanley FJ. Intrapartum asphyxia: a rare cause of cerebral palsy. J Pediatr 1988;112:515.

17. Pharoah POD, Platt MJ, Cooke T. The changing epidemiology of cerebral palsy. Arch Dis Child 1996;75:F169.

18. Stanley FJ, Watson L. The cerebral palsies in Western Australia: trends, 1968-1981. Am J Obstet Gynecol 1988;158:89.

19. MacGillivray I, Campbell DM. The changing pattern of cerebral palsy in Avon. Paediatr Perinat Epidemiol 1995;9:146.

20. Shevell MI, Majnemer A, Miller SP. Neonatal neurologic prognostication: the term asphyxiated newborn. Pediatr Neurol 1999;21:776-784.

21. Low JA, Galbraith RS, Muir DW, et al. Motor and cognitive deficits after intrapartum asphyxia in the mature fetus. Am J Obstet Gynecol 1988;158:356-361.

22. Lebeer J. How much brain does a mind need? Scientific, clinical and 
educational implications of ecological plasticity. Dev Med Child Neurol 1998; 40: 352-357.

23. Nelson KB, Leviton A. How much of neonatal encephalopathy is due to birth asphyxia? Am J Dis Child 1991;145:1325-1331.

24. Nelson KB, Emery ES. Birth asphyxia and the neonatal brain: what do we know and when do we know it? Clin Perinatol 1993;20:327-344.

25. Leviton A, Nelson KB. Problems with definitions and classifications of newborn encephalopathy. Pediatr Neurol 1992;8:85-90.

26. Volpe JJ. Hypoxic-ischemic encephalopathy: clinical aspects. In: Neurology of the Newborn, 3rd Ed. Philadelphia: WB Saunders, 1995;314-369.

27. Freeman JM, Nelson KB. Intrapartum asphyxia and cerebral palsy. Pediatrics 1988;82:240-249.

28. Sarnat HB, Sarnat MS. Neonatal encephalopathy following fetal distress: a clinical and electroencephalographic study. Arch Neurol 1976;33:696-705.

29. Perlman JM. Systemic abnormalities in term infants following perinatal asphyxia: relevance to long-term neurologic outcome. Clin Perinatal 1989;16:475-484.

30. Holmes GL, Lombroso CT. Prognostic value of background patterns in the neonatal EEG. J Clin Neurophysiol 1993;10:323-352.

31. Majnemer A, Rosenblatt B. Evoked potentials as predictors of outcome in neonatal intensive care unit survivors: review of the literature. Pediatr Neurol 1996;14:189-195.

32. Majnemer A, Rosenblatt B, Riley P. Prognostic significance of the auditory brain stem evoked response in high-risk neonates. Dev Med Child Neurol 1988;30:43-52.

33. Whyte HE. Visual-evoked potentials in neonates following asphyxia. Clin Perinatol 1993;20:451-461.

34. Lipp-Zwahlen AE, Deonna T, Chrzanowski R, Micheli JH, Calame A. Temporal evolution of hypoxic-ischaemic brain lesions in asphyxiated full-term newborns as assessed by computerized tomography. Neuroradiology 1985; 127:138-144.

35. Barkovich AJ, Hajnol BL, Vigneron D, et al. Prediction of neuromotor outcome in perinatal asphyxia: evaluation of MR scoring systems. Am J Neuroradiol 1998;19:143-149.

36. Beaulieu C, D'Arceuil H, Hedehus M, et al. Diffusion weighted magnetic resonance imaging: theory and potential applications to child neurology. Sem Pediatr Neurol 1999;6:87-100.

37. Schaefer GB, Bodensteiner JB. Evaluation of the child with idiopathic mental retardation. Pediatr Clin North Am 1992; 39: 929-943

38. Volpe JJ. Hypoxic-ischemic encephalopathy: clinical aspects. In: Neurology of the Newborn; 4th Ed. Philadelphia: WB Saunders, 2000: 331-394.

39. Hill A, Volpe J. Perinatal asphyxia: clinical aspects. Clin Perinatol 1989;16:435-457.

40. American Academy of Pediatrics, ACOG. Relationship between perinatal factors and neurologic outcome. In: Poland R, Freeman R, eds. Guidelines for Perinal Care. Elk Grove Village, IL: American Academy of Pediatrics, 1992:221-224.

41. MacLennan A, Force ICPT. A template for defining a causal relation between acute intrapartum events and cerebral palsy: international consensus statement. Br Med J 1999;319:10541059.

42. Robertson CM, Finer NN. Long-term follow-up of term neonates with perinatal asphyxia. Clin Perinatol 1993;20:483-500.

43. Hollier LM. Can neurological injury be timed? Sem Perinatol 2000; 24: 204-214.

44. Benirschke K. The placenta in the litigation process. Am J Obstet Gynecol 1990;162:1445-1450.

45. Miller PW, Coen RW, Benirschke K. Dating the time interval from meconium passage to birth. Obstet Gynecol 1985;66:459-462.

46. Fujikura T, Klionsky B. The significance of meconium staining. Am J Obstet Gynecol 1975;121:45-50.

47. Strauss DJ, Shavelle RM, Anderson TW. Life expectancy in children with cerebral palsy. Pediatr Neurol 1998;13:143.

48. Chrichton JV, MacKinnon M, White CP. The life expectancy of persons with cerebral palsy. Dev Med Child Neurol 1995;37:567576.

49. Strauss DJ, Shavelle RM. Life expectancy of adults with cerebral palsy. Dev Med Child Neurol 1998;40:369-375. 